\title{
DESAIN SARANA BAWA DENGAN MEJA PORTABEL UNTUK PERALATAN MENGGAMBAR ILUSTRATOR DIGITAL
}

\author{
Hilvan Maulana \\ Mahasiswa Program Studi Desain Produk, Jurusan Desain \\ Politeknik Negeri Samarinda \\ Dwi Cahyadi \\ Staf Pengajar Program Studi Desain Produk, Jurusan Desain \\ Politeknik Negeri Samarinda \\ Email:dwi_polnes@yahoo.co.id
}

\begin{abstract}
ABSTRAK
Menggambar adalah kegiatan meniru barang, manusia, binatang dan sebagainya yang dibuat dengan coretan pensil atau alat lainnya pada sebuah media. Orang yang menggambar dengan teknik digital atau bekerja sebagai pembuat ilustrasi digital biasa disebut sebagai Ilustrator Digital. Meskipun ilustrator digital sudah merupakan profesi yang memiliki peralatannya sendiri untuk dipakai akan tetapi belum ada media atau sarana bawa yang dikhususkan untuk membawa peralatan menggambar tersebut. Selain sarana bawa, meja yang bisa dibawa kemanapun saat pergi keluar dapat menjadi opsi tambahan ketika seorang ilustrator ingin menggambar di luar di tempat yang tidak tersedia meja. Tujuan yang ingin dicapai dalam perancangan produk ini adalah membuat produk berupa sarana bawa dan penyimpanan untuk peralatan menggambar Ilustrator Digital yang ergonomis dan sesuai dengan karakter ilustrator digital, memiliki dimensi yang sesuai dengan peralatan menggambar yang dibawa dan dapat dijadikan alas untuk menggambar. Dengan berbagai metode perencanaan dan perancangan yang diantaranya adalah pengumpulan data, konsep desain, alternatif desain, pengembangan desain hingga mencapai desain akhir, diharapkan usulan desain ini dapat memberi masukan bagi pihak-pihak terkait untuk dapat melengkapi hal-hal yang belum tercapai pada Desain Sarana Bawa Dengan Meja Portabel Untuk Peralatan Menggambar Ilustrator Digital ini.
\end{abstract}

Kata kunci: ilustrator digital, sarana bawa, meja portabel, peralatan menggambar 
Vol. 6, No. 2, April 2019

\section{ABSTRACT}

Drawing is an activity to imitate goods, humans, animals and so on that are made with pencil strokes or other tools on a media. People who draw with digital techniques or work as digital illustration makers are commonly referred to as Digital Illustrators. Even though digital illustrators are already professions that have their own equipment to use, there is no media or means to carry specifically to carry the drawing equipment. In addition to carrying facilities, a table that can be carried anywhere when going out can be an additional option when an illustrator wants to draw outside where there is no table. The goal to be achieved in designing this product is to make a product in the form of a vehicle and storage for drawing equipment Digital illustrators who are ergonomic and in accordance with the character of digital illustrators, have dimensions that are suitable for drawing equipment that can be used as a base for drawing. With a variety of planning and design methods which include data collection, design concepts, alternative designs, development of designs to achieve the final design, it is expected that this design proposal can provide input for relevant parties to be able to complete the things that have not been achieved in the Carrying Facilities Design With Portable Tables For Digital Illustrator's Drawing Equipment.

Keywords: digital illustrator, means of carrying, portable desk, drawing equipment

\section{Pendahuluan}

Menggambar adalah kegiatan meniru barang, manusia, binatang dan sebagainya yang dibuat dengan coretan pensil atau alat lainnya pada sebuah media. Orang yang menggambar dengan teknik digital atau bekerja sebagai pembuat ilustrasi digital biasa disebut sebagai Ilustrator Digital. Meskipun istilah ini tidak begitu banyak diketahui masyarakat awam akan tetapi istilah Digital Illustrator merupakan sebutan yang dikenal dalam masyarakat global terutama yang berkecimpung dalam bidang tersebut dikarenakan kebanyakan ilustrator digital bekerja sebagai pekerja lepas atau dibawah naungan suatu perusahaan yang kebanyakan kegiatannya dilakukan secara online. Dalam aktivitas menggambar digital diperlukan adanya perangkat seperti laptop, mouse atau pen tablet yang berukuran cukup besar. Kegiatan menggambar sendiri biasa dilakukan di dalam rumah, akan tetapi terkadang peralatan menggambar ini dibawa keluar untuk keperluan tertentu ataupun sekedar mengganti suasana agar tidak jenuh saat menggambar. Tempat yang cocok untuk menggambar di luar adalah tempat yang memiliki fasilitas seperti meja, kursi atau-

pun lesehan dan yang terpenting ada tempat untuk bersandar, tempat charging dan suasananya tidak ramai (Azmi, 2018).

Untuk membawa peralatan menggambar tersebut seorang ilustrator digital ataupun orang yang melakukan kegiatan menggambar digital biasa menggunakan sarana bawa berupa tas. Penggunaan tas biasa ini membuat peralatan gambar yang ada di dalam tas seringkali terguncang saat dibawa dan bercampur dengan barang-barang lain yang ditakutkan dapat menyebabkan terjadinya cacat fisik berupa goresan atau lecet pada peralatan gambar. Selain itu, keperluan akan meja kecil jika kegiatan menggambar akan dilakukan dengan duduk di lantai atau lesehan juga diperlukan dikarenakan meja laptop ataupun meja lipat yang ada sekarang tidak memiliki ukuran yang tepat untuk penataan peralatan gambar itu sendiri.

Belum ada ditemukan sarana bawa yang tepat untuk membawa peralatan gambar digital meskipun ilustrator digital sendiri merupakan suatu pekerjaan yang memiliki peralatan atau propertinya sendiri yang digunakan dalam kegiatannya. Selain itu meja dengan ukuran yang sesuai dengan 
Hilvan Maulana, Dwi Cahyadi, Desain Sarana Bawa Dengan Meja Portabel Untuk Peralatan Menggambar Ilustrator Digital

penataan peralatan tersebut juga belum ada kecuali jika dipesan sendiri. Dengan demikian, sarana bawa sekaligus meja untuk peralatan menggambar digital ilustrator ini menjadi sangat dibutuhkan dan hal tersebut menjadi dasar dari perancangan produk ini.

\section{Metode Perancangan}

Dalam mendesain produk ini menggunakan metode perancangan dengan tahapan - tahapan yang harus dilakukan secara terus menerus, yaitu:

\subsection{Preliminary Design}

Pengumpulan data dari informasi, analisis data berdasarkan konsep desain makro yang meliputi analisis konsep (konsep fungsi, konsep pemakaian, pemakaian pasar, dan konsep produk), penyusunan program desain sketsa awal. Bagian ini terdiri dari : Problem Formulation, Literature Review

\subsection{Design Development}

Pada tahap ini dibuat alternatif gambar komponen sertan rancangan secara wire diagram dengan bentuk sketsa dan 3D (tiga dimensi ) dari bagian yang tertera terdiri dari: Alternative Design, dan Alternative Development of Design

\subsection{Final Design \& Prototype}

Dibuat gambar-gambar yaitu dengan presentasi 3D dan gambar teknik (gambar-gambar tampak, potongan, gambar detail dan spesifikasi teknik produk) tahapan selanjutnya adalah pembuatan komponen-komponen dilakukan assenbling (exploded) atau perakitan sehingga menjadi produk (prototype).

\section{Pembahasan}

\subsection{Studi Aktivitas dan Kebutuhan}

Analisis aktivitas dan kebutuhan dilakukan untuk mengetahui aktivitas apa saja yang dilakukan oleh pengguna produk, setelah melakukan analisis aktivitas maka akan diketahui kebutuhan komponen-kom- ponen yang harus ada pada produk yang akan dibuat.

Karena sarana bawa ini akan digunakan sebagai sarana bawa peralatan menggambar digital maka peralatan menggambar yang akan dibawa adalah laptop, pen tablet, pen stylus, charger laptop dan sketchbook serta alat tulis pensil dan penghapus. Adapun analisis aktivitas dan kebutuhan desain sarana bawa peralatan menggambar dengan meja portabel untuk ilustrator digital ini adalah sebagai berikut :

Ilustrator digital biasanya akan meletakkan peralatan menggambar di tempat yang terpisah untuk menjaga peralatan mereka tetap aman, karena itu diperlukan wadah atau ruang yang berbeda untuk hampir setiap jenis peralatan yang dibawa, terutama bila peralatan itu tergolong peralatan yang mahal seperti laptop dan pen tablet sendiri. Untuk charger laptop dan alat tulis sendiri dapat digabung menjadi satu tempat karena ukurannya yang kecil, fleksibel dan tahan terhadap guncangan.

Selain membawa peralatan, dikarenakan adanya fitur meja portabel pada tas maka aktivitas menggambar juga seharusnya dapat dilakukan tanpa perlu mengeluarkan peralatan dari sarana bawa melainkan cukup dengan membuka fitur meja serta membuka penutup sarana bawa sehingga peralatan yang tertata pada tempatnya dapat langsung digunakan tanpa perlu dipindah-pindahkan.

Berdasarkan analisis aktivitas dan kebutuhan yang terdapat pada tabel serta keterangan di atas, maka telah didapatkan kesimpulan mengenai komponen-komponen apa saja harus ada dalam produk. Berikut fasilitas yang terdapat produk, ialah

- Memiliki space yang cukup untuk meletakkan peralatan menggambar dan tidak bersifat merusak barang-barang tersebut;

- Masing-masing alat yang akan diletakkan pada sarana bawa adalah laptop, pen tablet (beserta pen stylus nya), 
Vol. 6, No. 2, April 2019

sketchbook, charger laptop dan alat tulis disesuaikan dengan panjang, lebar dan tinggi peralatan yang telah dianalisis yaitu bila dirincikan, area laptop memiliki dimensi $34 \mathrm{~cm}$ x $24 \mathrm{~cm}$ x $3 \mathrm{~cm}$, area pen tablet memiliki dimensi $30 \mathrm{~cm} \times 21$ $\mathrm{cm} \times 0,8 \mathrm{~cm}$, area sketchbook memiliki dimensi $29 \mathrm{~cm} \times 20,5 \mathrm{~cm} \times 0,8 \mathrm{~cm}$, area charger yang disatukan dengan alat tulis adalah $28 \mathrm{~cm} \times 25 \mathrm{~cm} \mathrm{x} 3 \mathrm{~cm}$ dan area khusus penyimpanan meja portabel memiliki dimensi $34 \mathrm{~cm} \times 24 \mathrm{~cm} \times 5$ $\mathrm{cm}$.

\subsection{Analisis Ergonomi dan Anthropo- metri}

Dalam merancang sebuah produk, analisis ergonomi dan antropometri sangat diperlukan karena setiap pembuatan produk yang berhubungan dengan manusia harus mengutamakan faktor kenyamanan dalam penggunaan produk tersebut.

Analisis ergonomi dilakukan untuk meminimalkan resiko kesehatan dan keselamatan dan juga agar kenyaman dalam melakukan kegiatan menggunakan produk dapat maksimal. Ergonomi sangat diperlukan untuk merancang suatu produk. Aktivitas-aktivitas yang telah dianalisis membutuhkan fasilitas yang ergonomis agar kenyamanan pengguna ketika menggunakan produk terjamin. Ergonomi disini adalah kenyamanan dan keamanan yang diperlukan untuk melakukan aktivitas dengan produk sarana bawa peralatan menggambar digital dengan meja portabel untuk ilustrator digital yang menggunakan material yang tidak berbahaya digunakan, estetis, dan fungsional.

Aktivitas-aktivitas yang telah dianalisis membutuhkan fasilitas yang ergonomis agar kenyamanan pengguna ketika menggunakan produk ini terjamin. Berikut ini adalah titik-titik keergonomisan pada produk :

- Untuk faktor ergonomi pada meja portabel saat digunakan adalah terletak pada kaki mejanya, tinggi posisi meja harus sesuai dengan tinggi siku dalam posisi duduk (siku tegak lurus) rata-rata laki-laki dan perempuan usia remaja dan dewasa dan ditambahkan toleransi.

- Masa berat pikul atau jinjing produk meja lipat ditambah dengan sarana bawa juga fasilitas atau peralatan yang dibawa seperti laptop, pen tablet dan sketchbook tidak boleh melebihi beban ergonomis yang ditentukan untuk pengguna. Untuk beban yang dapat diangkat dengan cara dijinjing atau berupa handbag berat maksimumnya adalah $3-5 \mathrm{~kg}$. Untuk beban bawa yang diangkat dengan posisi seperti memakai tas selempang, bobot maksimum yang dapat diangkat adalah $10 \%$ dari berat badan orang tersebut. Untuk beban yang diangkat dengan bantuan bahu atau seperti membawa ransel adalah $20 \%$ dari berat orang yang membawanya, misalkan berat orang tersebut adalah $60 \mathrm{~kg}$ maka beban yang dapat dibawanya adalah 12 kg. (Novirdayani, 2016)

- Panjang dan lebar meja harus mampu menampung dan menjadi alas untuk 2 peralatan utama, yaitu laptop dan pen tablet dengan posisi yang tepat.

- Saat meja digunakan untuk aktivitas menggambar, harus sesuai dengan jarak lihat pengguna yang tidak terlalu rendah dan tidak terlalu tinggi agar badan pengguna tidak membungkuk ke depan.

Antropometri yang digunakan untuk mengetahui tinggi meja adalah dimensi antropometri tinggu siku dalam posisi duduk (siku tegak lurus). Jenis antropometri yang digunakan adalah persentil rata-rata wanita, yaitu $230 \mathrm{~mm}$. Tinggi ini adalah tinggi maksimal meja. Sehingga untuk perancangan meja portabel dalam tugas akhir ini digunakan ukuran $20 \mathrm{~cm}$. 
Hilvan Maulana, Dwi Cahyadi, Desain Sarana Bawa Dengan Meja Portabel Untuk Peralatan Menggambar Ilustrator Digital

\section{Menentukan Lebar Meja}

Antropometri yang digunakan untuk mengetahui lebar meja adalah dimensi antropometri jarak genggaman tangan kepunggung pada posisi tangan ke depan. Jenis antropometri yang digunakan adalah nilai persentil $5 \%$ wanita, yaitu 650 atau 65 $\mathrm{cm}$ sehingga diambil ukuran $62 \mathrm{~cm}$ dari antropometri diatas. Ukuran ini adalah ukuran maksimal untuk lebar meja dalam perancangan meja portabel ini yang kemudian disesuaikan dengan ukuran benda yang akan diletakkan diatasnya, yaitu laptop dan pen tablet menjadi $33,5 \mathrm{~cm}$.

\section{Menentukan Panjang Meja}

Antropometri yang digunakan untuk mengetahui panjang meja adalah dimensi antropometri lebar rentang tangan. Jenis antropometri yang digunakan adalah nilai persentil wanita $5 \%$, yaitu $149 \mathrm{~cm}$ sehingga diperoleh ukuran $140 \mathrm{~cm}$ dan $70 \mathrm{~cm}$ jika dibagi 2. Karena meja ini merupakan meja lipat maka ukuran yang artinya jika dilipat akan menjadi setengah ukuran asli. Ukuran ini adalah ukuran maksimal untuk panjang meja ini yang kemudian disesuaikan dengan ukuran benda yang akan diletakkan diatasnya, yaitu laptop dan pen tablet menjadi 50 $\mathrm{cm}$. Karena meja ini adalah meja lipat dimana meja untuk alas laptop dan pen tablet berbeda, maka ukuran semula $50 \mathrm{~cm}$ akan dikali 2 menjadi $100 \mathrm{~cm}$.

\subsection{Analisis Sistem}

Analisis sistem dilakukan guna menemukan sistem apa saja yang akan diaplikasikan pada produk. Berikut material serta sistem-sistem yang akan diaplikasikan pada produk adalah:

\section{Sistem Pada Sarana Bawa}

Ladder lock slider digunakan pada tali tas untuk mengatur panjang tali tas bagian bawah agar cocok dengan pengguna. Hook and Loop Tape digunakan sebagai sistem sambungan khusus antar kain yang dapat dibuka dan ditutup untuk mengam- bil barang yang ada di dalam dan sekaligus berfungsi sebagai pengaman. Zipper (Resleting) menggunakan Plastic Zipper dikarenakan bahan tidak akan berkarat serta ringan dan tidak diperlukan fleksibilitas yang lebih untuk produk ini.

\section{Sistem Sambungan}

Metal buckle digunakan pada tiap ujung tali untuk mengaitkan tali tas pada badan sarana bawa atau meja. Sistem sambungan jahitan yang memungkinan akan diaplikasikan pada produk ini adalah jahitan kunci. Jahitan kunci dipilih karena merupakan jahitan umum dengan konstruksi kuat yang cocok dipakai untuk kain-kain tebal seperti kain untuk tas. Selain itu jahitan ini memberikan bentuk yang sama pada sisi atas dan bawahnya serta merupakan jahitan yang sulit untuk dilepas.

\section{Sistem Pada Meja Lipat}

Paku keling digunakan sebagai sistem sambung utama kerangka alumunium karena pemasangannya yang cepat dan rapi sehingga menjadi sistem sambung paling cocok untuk kerangka alumunium. Jenis engsel yang diterapkan pada sistem lipat untuk produk adalah Engsel Piano karena panjang sehingga dapat menghubungkan 2 bagian lebih kuat dan ukurannya yang tipis. Jenis sistem kuncian yang cocok untuk diterapkan pada produk adalah briefcase latch dengan jumlah 2 pada sisi samping agar lebih kuat. Sistem kuncian tanpa pengunci khusus dapat mengurangi kehilangan kunci dengan tetap memastikan kedua sisi terkunci rapat. Sistem handle yang cocok untuk diterapkan pada produk adalah webbing tape karena harganya yang murah dan kuat, meski ukurannya tidak setebal tali kulit, webbing tape masih sangat kuat sebagai sistem handle karena itu webbing tape sering digunakan pada tas.

Jenis finishing yang cocok untuk diterapkan pada produk adalah finishing stiker vinyl dengan laminasi doff karena cocok diaplikasikan pada permukaan alas 
Vol. 6, No. 2, April 2019

meja menggambar, bisa mendesain motif sendiri dan pilihan warna sendiri serta tidak mudah kotor.

\subsection{Analisis Bentuk}

Dalam menentukan bentuk, dilakukan pendekatan melalui eksisting produk yang sudah ada dan pendekatan terhadap jenis gaya desain. Untuk menganalisis gaya desain yang akan diaplikasikan adalah dengan cara memakai beberapa indikator yang dijadikan patokan pertimbangan. Indikator untuk yang dipakai untuk pemilihan gaya desain adalah kemudahan produksi, cocok untuk berbagai situasi dan kondisi, sesuai dengan peralatan yang akan dibawa, yaitu peralatan menggambar digital.

Setelah menganalisis kriteria dari masing-masing gaya desain maka gaya desain yang terpilih adalah gaya desain modern karena gaya desain modern lebih mudah diproduksi, tidak memiliki ornamen-ornamen yang detail, cocok untuk berbagai situasi dan kondisi serta sesuai dengan peralatan yang dibawa. Sedangkan untuk jenis tas yang dipilih adalah tas ransel yang sudah dilakukan survey terhadap pengguna peralatan menggambar digital, kuesioner terdapat pada halaman lampiran.

\subsection{Analisis Warna}

Setelah dilakukan analisis terhadap peralatan menggambar digital didapatkan beberapa warna yang masuk dalam kategori warna asosiatif. Warna hitam, abu-abu dan putih terpilih sebagai warna dominan karena banyak perangkat atau peralatan yang digunakan oleh ilustrator digital didominasi oleh warna-warna ini dan juga merupakan warna yang paling umum dipakai oleh banyak merk peralatan yang dibawa seorang ilustrator digital. Warna biru, merah dan hijau terpilih sebagai warna aksen karena banyak merk peralatan menggambar digital yang memiliki warna aksen tersebut seperti Wacom seri intuos, Wacom seri ctl juga laptop Acer dan Asus.

\subsection{Pengembangan Desain}

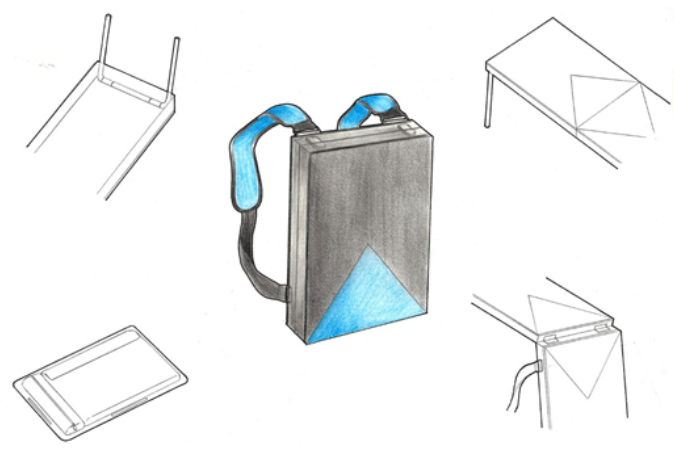

Sumber : Maulana, 2019

Gambar 1. Sketsa Desain Awal

Pada sketsa desain awal dalam gambar 1, alas meja dibuat persegi panjang tanpa lengkungan pada sisinya, hal ini akan mempermudah proses produksi dan pada sudut setiap sisi alas mejanya di amplas hingga halus. Memiliki 2 pengunci dibagian atas dan memiliki tali berwarna biru yang terpasang pada sisi atas dan samping alas meja. Memiliki engsel pada posisi bawah sarana bawa untuk melipat meja. Motif biru berbentuk segitiga berada pada bagian bawah permukaan alas sarana bawa.

Pada pengembangan desain awal, 5 rangka alumunium mencakup hingga permukaan meja dengan penyangga dibagian dalam untuk membuat alas meja berada pada posisinya yang membuat strukturnya kuat. Memiliki tali bagian atas yang berwarna dasar biru dengan tali tambahan untuk memperkuat struktur tali tas yang memiliki warna hitam begitu juga dengan tali bawah dan samping. Pada permukaan meja terdapat motif sederhana berupa persegi panjang yang terbagi menjadi 2 dan menimbulkan kesan modern. Memiliki kaki meja yang berbentuk persegi panjang. 


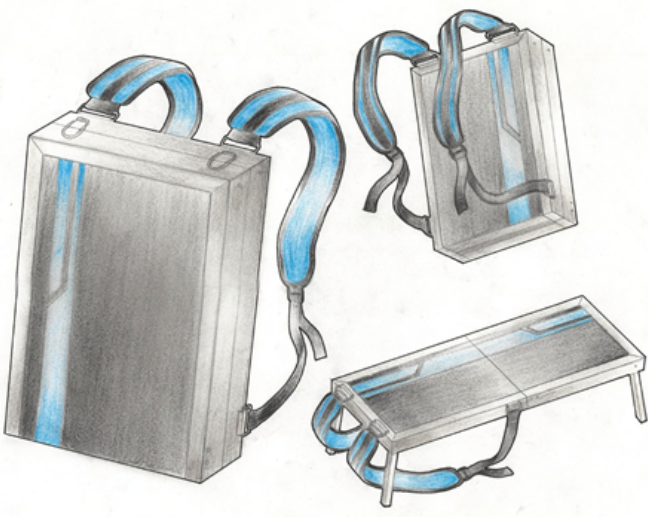

Sumber : Maulana, 2019

Gambar 2. Pengembangan Desain Awal

Setelah mendapatkan desain terpilih beberapa sketsa pengembangan, maka desain ini dibuat kembali sketsanya dalam bentuk yang lebih rinci beserta dengan gambar presentasi $3 \mathrm{~d}$. gambar tersebut dijadikan acuan dalam pembuatan prototipe produk, yang akan dikembangkan menjadi produk massalyang bisa diproduksi di indstri untuk dijual ke pasar.

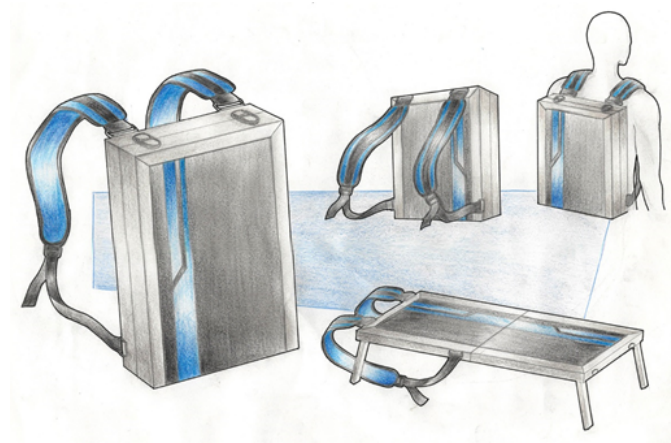

Sumber : Maulana, 2019 Gambar 3. Sketsa Desain Akhir

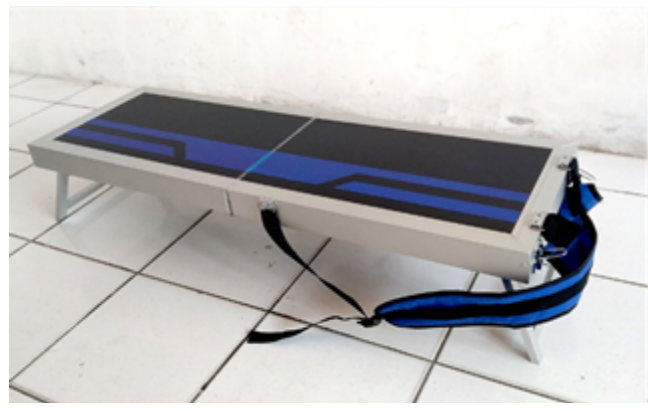

Gambar 4. Prototipe

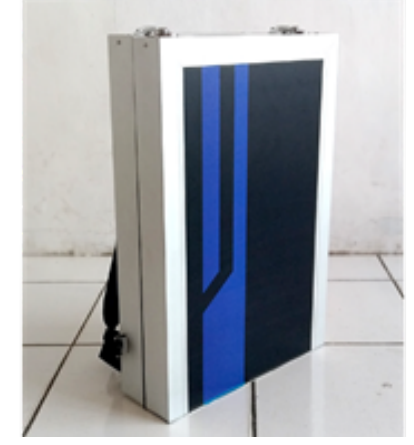

Gambar 5. Prototipe

\section{Kesimpulan}

Dengan dibuatnya Desain sarana bawa dengan meja portabel untuk peralatan menggambar ilustrator digital ini, diharapkan para ilustrator digital dapat lebih mudah membawa peralatan menggambar mereka dan dapat digunakan dengan lebih praktis ketika dibutuhkan. Dan semoga desain ini mampu bermanfaat untuk pengembangan produk tersebut.

Desain sarana bawa dengan meja portabel untuk peralatan menggambar ilustrator digital ini memiliki ukuran yang pas dengan ukuran peralatan yang ada untuk mencegah peralatan terguncang atau tergores saat dibawa dalam tas.

Saran

Dari data yang didapatkan, dapat diambil fakta bahwa produk sarana bawa untuk peralatan menggambar masih belum diproduksi, maka sebaiknya penyediaan produk sarana bawa dengan meja portabel ini dapat direalisasikan untuk kedepannya. Dari survey minat juga terdapat beberapa saran untuk produk, yaitu dimensi yang lebih bervariasi, penambahan jumlah kantong, kaki meja yang bisa diatur ketinggiannya dan memiliki bantalan pada sisi punggung agar lebih nyaman dipakai. 
Vol. 6, No. 2, April 2019

DAFTAR PUSTAKA

Affendi, Yusuf. (1978). Desain Warna, Susunan dan Fungsinya, Institut Teknologi, Bandung

https://www.scribd.com/document/368408584/Susunan-Warna-docx

Cahyadi, Dwi. (2014). Aplikasi Mannequin Pro untuk Industri. Leutika Pro: Yogyakarta http://www.leutikaprio.com/main/media/sample/Aplikasi\%20Mannequin\%20Pr o \% 20 untuk\%20Desain\%20Industri\%20DS\%20\%2017\%20APRIL\%202014.pdf

Nurmianto, Eko. (1996). Ergonomi, Konsep Dasar dan Aplikasinya. PT. Guna Widya :

Surabaya

http://www.leutikaprio/main/media/sample/Aplikasi\%20Mannequin\% 20Pr

Lomber-bags. (2016). Berbagai Macam Jenis Tas. Diakses 3 Juli 2016.

http://www.lombergbags.com/blog/2016/07/berbagai-macam-jenis-tas 